\title{
Did Food Insecurity rise across Europe after the 2008 Crisis? An analysis across welfare regimes
}

\author{
Owen Davis* and Ben Baumberg Geiger** \\ *School of Social Policy, Sociology and Social Research (SSPSSR), University of Kent, Canterbury, Kent, CT2 7NZ \\ E-mail: od60@kent.ac.uk \\ **School of Social Policy, Sociology and Social Research (SSPSSR), University of Kent, Canterbury, Kent, CT2 7NZ \\ E-mail: b.b.geiger@kent.ac.uk
}

Since the 2008 crisis, there has been a sharp rise in demand for food aid across highincome countries, spurring increased academic interest in the issue of food insecurity. Despite this heightened interest, there remains a paucity of quantitative evidence on trends in the prevalence of food insecurity in rich countries. In this context, the following article presents 'direct' evidence on recent patterns of food insecurity across countries and welfare regimes using secondary analysis of the European Quality of Life Survey. It uses an item which has been a longstanding component of deprivation scales, 'could your household afford a meal with meat, chicken or fish every second day if you wanted it?', to investigate two hypotheses. First, we explore whether food insecurity has risen since the 2008 crisis as the rise in food aid suggests. Second, we examine if this rise has varied across welfare regimes, if it has occurred at all. The article finds evidence to support both contentions: food insecurity has risen across many European countries and has varied by welfare regime. It also finds that contrary to expectations, the sharpest rise was in the Anglo-Saxon countries of Ireland and the UK, rather than Southern or Eastern European countries.

Key words: Food banks, food insecurity, crisis, welfare regimes.

\section{Introduction}

The ownership of food is the most basic of property rights (Sen, 1983: 45). While the ability to be secure in one's food consumption is an issue that is often thought to be restricted to low-income countries, recently food insecurity has featured more frequently within policy debates in high-income countries (Dowler et al., 2011), following a dramatic and noticeable growth in demand for food aid (see below).

Academic research on food aid and food insecurity in high-income countries has started to grow as the problem itself has increased. A recent special issue of this journal included a collection of articles examining food insecurity in Denmark (Nielsen et al., 2015), Finland (Silvasti, 2015), Germany (Pfeiffer et al., 2015) and the UK (Dowler and Lambie-Mumford, 2015; Lucas et al., 2015). Each article argued that food insecurity was a pertinent issue within their country, and provided important insights into its development. Yet only one of these articles utilised large-scale quantitative data to compare rates of food insecurity across countries (Pfeiffer et al., 2015). This is a limitation noted by 
Lambie-Mumford and Dowler (2015) in the same issue, and they argue for more systematic (and comparable) evidence on food insecurity across Europe and other high-income countries. The need for this evidence is urgent given continued political controversy such as in the UK, discussed below - around whether food insecurity has risen alongside rising poverty and food bank usage.

In this context, the current article provides new evidence on food insecurity across European countries and welfare regimes. It hypothesises that food insecurity may vary across countries and welfare regimes given differences in the extent to which they protect against risk factors for food insecurity, such as poverty and social exclusion, and how they shield their citizens from the impact of economic crisis (Fouarge and Layte, 2005; Ogg, 2005; Brady, 2005).

\section{Trends in the demand for food aid}

Food aid refers to a range of community-oriented support systems, including food stamps and vouchers, prepared onsite food provision and various forms of offsite food distribution such as 'soup runs' (Lambie-Mumford et al., 2014: iv). Since the 2008 crisis, there has been a surge across wealthy countries in the numbers of people receiving food aid. The rise is illustrated in data from the European Food Aid to the Most Deprived Persons programme (European Commission, 2012), which document a rise from 14.4 to 19.0 million beneficiaries between 2008 and 2011.

Data on food aid remain scarce however, and are not routinely monitored by many European governments. As such, most of the evidence on food aid is derived from national statistics from non-government organisations (NGOs) which manage the distribution of food aid through food banks. In the UK, for instance, recent statistics from The Trussell Trust (2014: 2) show that food bank usage has risen annually since 2010-11, and that enough emergency food assistance was distributed in 2013-14 to feed over 900,000 people. The equivalent organisation in France, 'Restos du Coeur', also notes year-on-year rises in food bank recipients since 2008 (Expatica, 2009), whilst in Germany the main umbrella body 'Die Tafeln' now supplies food to 1.5 million people, although the rise in beneficiaries occurred prior to 2008 and is often attributed to the 2005 Hartz IV benefit reforms $^{1}$ (Selke, 2013). Finally, in Belgium, food banks reported that up to 121,000 people received food aid in 2012, representing an increase of 4,500 from 2011 and double the number in 1995 (Expactica, 2013).

\section{Food aid and food insecurity}

Yet food bank statistics are only an 'indirect' measure (in Riches' 1996a terms) of food insecurity, the main concept of interest (see Tarasuk and Beaton, 1999; Hamelin et al., 2002; Loopstra and Tarasuk, 2012). Food insecurity is a broad concept that involves issues of 'access, sufficiency ... vulnerability ... and sustainability' (Maxwell, 1996: 292). It is concerned with the structural factors which determine access to food entitlements (Sen, 1983), as well as whether available food is sufficient to meet basic nutritional needs. Food insecurity is also often linked with issues of inequality, such as how and why vulnerability to food insecurity is differentially spread across populations (Watts and Bohle, 1993). Last, food insecurity is a concept which contends with how sustainable a person's access 
to food is, i.e. is their situation chronic or temporary? (Maxwell and Frankenberger, 1992: 48).

Food bank data are not only an indirect measure of this concept, but there are also reasons to call in to question their validity - and indeed, the UK government and right-wing media have publicly criticised the claims made using food bank data. Doublemeasurement and over-estimation are common problems with food bank statistics (Riches, 1996a), and the Trussell Trust figures above were critiqued on these grounds by the fact-checking organisation 'Full Fact' (2015). Food banks might also have political or ideological motivations to over-estimate findings (as argued in The Daily Mail in the UK; Shipman, 2014). Lord Freud, a minister in the Department for Work and Pensions (DWP), argued that the expansion of food banks could simply be the result of more people taking advantage of a more readily available service, rather than a genuine rise in need (Hansard, 2013). There is little evidence as to whether this is really the case (Lambie-Mumford et al., 2014: xii), partly due to the dearth of food bank literature more generally. However, there is some support from qualitative research with frontline food bank staff (Sosenko et al., 2013), and it is plausible that there is some interrelationship between supply and demand for food aid.

Yet there are also reasonable grounds to think that the rise in food aid might partly represent a genuine rise in food insecurity:

- While there are reasons that food aid is an over-estimate of food insecurity, this may be balanced out by reasons that it provides under-estimates. Stigma around usage can create non take-up, with evidence suggesting that many food insecure households do not access food banks (Riches, 2002: 650; Loopstra and Tarasuk, 2012: 508). Some food insecure households will also use other methods of coping, such as eating less preferred foods, skipping meals, borrowing money to buy food and limiting portion size, amongst others (Maxwell, 1996: 295).

- Evidence shows that, in general, food bank data provide a reasonable estimate of the scale of food insecurity at a given point in time (Riches, 1996a: 50). Both qualitative and quantitative research from the United States (US) (Daponte et al., 1998; Borjas, 2004; Bhattarai et al., 2005; Coleman-Jenson et al., 2013) and Canada (Tarasuk and Beaton, 1999; Loopstra and Tarasuk, 2012) suggests that there is a strong association between food insecurity and receipt of food aid. Further reviews of evidence from elsewhere draw the same conclusions (Lambie-Mumford et al., 2014: 28).

- There are various reasons why food insecurity may have risen over the course of the 2008 crisis. For example, in the UK, food banks, social justice advocacy organisations, and the left-wing media argue that rising food bank usage does represent a genuine increase in food insecurity, which they partly relate to changes to the benefits system and partly to wider structural issues such as unemployment and falling real incomes (Cooper and Dumpleton, 2013: 3; The Trussell Trust, 2014; Buchanan, 2014; Butler, 2014). Academic research remains scarce, with one recent article in the British Medical Journal providing the only known source of peer-reviewed evidence on this issue (Loopstra et al., 2015). In this, the authors find that food bank usage has been concentrated in areas where there have been the sharpest cuts to local authority and central welfare spending and the highest rates of benefit sanctions and unemployment.

In sum, evidence suggests that food aid data are a defensible proxy for food insecurity at a single point in time. Moreover, the rise in food aid is unquestionable. The issue in 
post-2008 Europe, however, is to what extent rising food bank use reflects rising food insecurity. This is a different and more contentious argument, for which we need direct data on food insecurity, to which we now turn.

\section{Direct data on food insecurity}

Until recently, the only published international trend data on food insecurity - and the data used by the British Prime Minister when challenged to contest the idea that food insecurity has risen (Hansard Commons, 2014) - are contained in the Organisation for Economic Co-operation and Development (OECD) publication Society at a Glance (2014: 27-8), based on the question, 'Have there been times in the past 12 months when you did not have enough money to buy food that you or your family needed?'. These data show that across the OECD, there was a marginal rise in food insecurity from 13.6 per cent in 2006-7 to 14.7 per cent in 2011-12 (and within the EU, a rise from 7.7 to 8.7 per cent), and a fairly substantial decline from 9.8 to 8.1 per cent within the UK. However, there are several problems with these data. First, the analysis is unreplicable - the data come from the Gallup World Poll, a private dataset that is only available to researchers for a fee of over $£ 100,000$. Second, the sample size within the UK seems sufficiently small that the falling food insecurity over time is non-significant (as confirmed in a private conversation with Gallup), and no significance testing of trends is reported by the OECD. Finally, the methodology of the Gallup World Poll seems to have changed over time. In the UK, sampling was via landline telephone in 2005-10 (which itself is less desirable than face-to-face interviewing), but via landline and mobile telephone from 2011.

This evidence has recently been supplemented by Pfeiffer et al. (2015), who use data from EU - Statistics on Income and Living Conditions (EU-SILC) to investigate 2005-12 trends in food insecurity, as measured by ability to afford a meal with meat, chicken or fish every other day. They show a post-crisis rise across the EU27, and dramatic increases in food insecurity in the UK and Greece, although in both cases the steepest rise did not occur until several years after the beginning of the crisis (between 2011 and 2012). In contrast, in Germany they find that food insecurity was not affected by the crisis and actually declined from 11.0 per cent in 2005 to 8.2 per cent in 2012. However, once more there are considerable limitations with the analysis. First, EU-SILC is not a true comparative survey; instead it is underpinned by an EU Regulation that requires each country to deliver measures of certain pre-defined outcomes. There are therefore considerable variations between countries in question wording, survey mode (telephone vs. face-to-face), non-response rate and use of proxy respondents (varying from $<10$ per cent to 50 per cent of respondents) (Eurostat, 2010), all of which make it more difficult to be confident that the results are comparable across countries. Second, while Pfeiffer et al.'s analysis is an important contribution to our knowledge, it primarily concentrates on differences between three countries (UK, Germany and Greece) rather than across European welfare states more broadly, and moreover does not examine whether these within-country trends are statistically significant.

In summary, the small amount of evidence that exists suggests that food insecurity may have risen across Europe on average (although not uniformly), but the evidence remains limited. In this article, we present the first analyses of trends in food insecurity using the 2003, 2007 and 2011 waves of the European Quality of Life Survey 
(EQLS) - a more transparent survey than the Gallup World Poll, and with certain advantages over EU-SILC. This allows us to examine which of the competing arguments about trends in food insecurity can be verified empirically.

\section{Food insecurity across welfare regimes}

We have so far implied that food insecurity may have risen and fallen in tandem across European countries - but there are good reasons to think this has not been the case. First, relationships between welfare regimes and poverty and social exclusion vary (Brady, 2005; Fouarge and Layte, 2005). Since the latter are considered to be indirect indicators of food insecurity (Riches, 1996a: 48), we may reasonably expect that food insecurity will similarly differ across regimes. Second, the social consequences of the economic crisis (e.g. rising unemployment, underemployment and poverty) have varied in magnitude across Europe (European Commission, 2013). These differences between countries have tended to cluster within geographical regions: southern and Eastern European countries such as Greece, Spain, Portugal, Estonia and Hungary have fared badly, whilst central and northern countries such as France and Germany have remained quite resilient (European Commission, 2013; Eurostat, 2015). Regional clusters correspond with regime types due to shared political, economic and cultural features of neighbouring countries (Avendano et al., 2009), thus providing further reason to expect variations in food insecurity across welfare regimes. Third, the impact of the crisis has varied depending on economic policies, and, in some cases, these policies fit with the ideology of the welfare state regime. For example, the UK - an Anglo-Saxon welfare regime (Ferrera, 1996) - has adopted a stringent set of austerity policies in line with a free-market economic approach (TaylorGooby, 2012).

Given that poverty rates and the consequences of crisis are related to welfare regimes, it seems appropriate to compare food insecurity across regimes too. While welfare regime classifications were originally theorised by Esping-Andersen (1990), we here adopt Ferrera's (1996) typology of 'Anglo-Saxon', 'Bismarckian', 'Scandinavian' and 'Southern' regimes. Unlike Esping-Andersen's model (1990), this classification accounts for the distinctive characteristics of Southern European countries. Following others (e.g. Eikemo et al., 2008), we add a fifth 'Eastern' regime, comprised of the eastern European countries available in EQLS that are members of the OECD (Czech Republic, Estonia, Poland, Slovenia, Slovakia and Hungary). This allows us to evaluate how successful formerly communist countries have been in protecting and maintaining the food security of their citizens over the course of the crisis. It is possible that enduring features of communist economic and social policy, such as state-subsidised food and rent, high wages and full employment, will have shielded citizens from food insecurity over this period (Deacon, 2000; Fenger, 2007). Yet since the transition from communism has been associated with high poverty rates, we could equally anticipate that food insecurity will be high across the period (Böhnke, 2008).

We would expect food insecurity to have risen the most in Southern and Eastern regimes (where the economic consequences of the crisis have been the greatest), and least in the Bismarckian and Scandinavian regimes (where economic consequences have been smaller and welfare states more developed). In the rest of the article, we test whether these expectations are borne out by the data. 


\section{Methods}

\section{Data and main outcome measures}

We use the EQLS waves in 2003, 2007 and 2011, sponsored by the European Foundation for the Improvement of Living and Working Conditions (Eurofound) and originally collected by Intomart GfK, TNS Opinion and Significant GfK. Each wave of the EQLS involved a random sample of the European adult population; the random samples varied between random selection from a pre-defined sample frame and a 'random route' method (see Web Appendix WA1 for full details). Response rates vary both between countries and within countries over time (see Web Appendix WA1), but with a few exceptions (Germany/France/UK 2003, Ireland/Sweden 2007, primarily with higher response rates) they vary between 25 per cent and 60 per cent. Response rate variations inevitably introduce an additional element of uncertainty into our analyses, but these are nearubiquitous in comparative research (the same problems are visible in EU-SILC), and EQLS has several strengths over EU-SILC: proxy interviews were not allowed in any of the waves, and all interviews were conducted face-to-face in respondents' own homes using standardised question wording. Despite its limitations, we believe that EQLS is therefore the best available data resource for researchers interested in developments in food insecurity across the recent crisis.

The only measure of food insecurity that is available both before and after the crisis in Europe is the question, 'Can I just check whether your household can afford a meal with meat, chicken or fish every second day if you wanted it?' This is a longstanding component of deprivation scales (cf. McKay, 2004; Lansley and Mack, 2015) and has several advantages as a measure of food insecurity. It focuses on an aspect of food consumption (meat/chicken/fish) that families economise on during periods of financial strain, and is less subjective than other measures (Maxwell, 1996; Dowler, 1998; Tarasuk and Beaton, 1999; Dowler, 2002; Bhattacharya et al., 2004; Coleman-Jensen et al., 2013; Lambie-Mumford et al., 2014). It also tells us about the extent of food deprivation - an important dimension of food insecurity. Yet it is not a perfect measure, partly because it only focuses on one aspect of the multifaceted concept of food insecurity. Other aspects - e.g. nutritional inadequacy, anxiety over food sufficiency and social stigma - are covered in measures such as the Radimer/Cornell hunger scale (Radimer, 1990), but are unfortunately not covered in any repeated cross-national surveys over this period.

However, one of the strengths of EQLS is that the pre-crisis waves (2003 and 2007) asked respondents about one further aspect of food insecurity: 'Has your household at any time during the past 12 months run out of money to pay for food?' While this is not the main outcome of interest here (it is not asked in 2011, so cannot tell us about trends over the crisis), this does allow us to check the overlap between the two measures, and the extent to which comparisons across countries are similar using both measures. While this does not overcome the conceptual limitations of our analysis, it does strengthen the conclusions we can draw.

Our measure of food insecurity also suffers from the same limitations as all such deprivation measures, in that people will vary in their desire for meat, chicken or fish every second day and in their willingness to admit they cannot afford it (McKay, 2004; Nolan and Whelan, 2010). Indeed, we know that individual consumption habits are culturally relative and the availability of good quality food varies (Naska et al., 2005). For example, 
in particular countries such as Greece, households of a lower social class consume a healthier diet due to the availability of oils, fruit and vegetables and fresh fish (Naska et al., 2005) and it is noted elsewhere that there is a less predictable relationship between fruit and vegetable consumption and social class in the southern European countries than in the northern ones (Trichopoulou et al., 2002; Naska et al., 2005). It is plausible therefore that a combination of cultural habits and a more equal distribution in access to food may make 'skimping' less of a common practice in certain countries (such as those in southern Europe), even during periods of crisis. Furthermore, it is also possible that the question (e.g. what 'afford' means) is interpreted differently in different countries. Yet this does not make comparative analysis impossible or meaningless. A systematic review of qualitative and quantitative studies by Coates et al. (2006) found clear commonalities in the experience of food insecurity across fifteen countries, including in food inadequacy and meal disruption - the measures used in this article. Furthermore, cultural differences are less problematic for investigating trends than for comparing countries per se.

\section{Analyses and other variables}

The analysis proceeds in three steps. First, we compare our two measures of food insecurity across the EQLS countries before the 2008 crisis, and examine the convergent validity of our two measures of food insecurity. Second, we examine trends in food insecurity (as measured by people's ability to afford meat/chicken/fish) across individual countries, comparing the pre-crisis period with the post-crisis period; the smaller 2003 and 2007 waves were pooled into a combined pre-crisis sample. Third, we construct a (logistic) regression model to test if there are significant differential impacts of the crisis on food insecurity in different welfare regimes, net of compositional differences between countries. We control for age (grouped into five bands), gender and single parent status, as single parents are known to be particularly vulnerable to food insecurity, even in economically buoyant times (Tarasuk and Beaton, 1999; Bhattarai et al., 2005; Coleman-Jensen et al., 2013). The risk of food insecurity is higher as the nurturing instinct of mothers and fathers often leads them to employ 'buffering' (Maxwell, 1996) strategies, i.e. sacrificing their own food to ensure their children are adequately fed (Campbell and Desjardins, 1989; Tarasuk and Maclean, 1990).

All analyses were conducted using Stata 12. The supplied weights were used, with sample members being weighted according to their country's population size (in sensitivity analyses we reweight so that respondents in each country count equally). We did not use multilevel models in this analysis as we were not aiming to partition variance between different levels (the particular strength of multilevel modelling). Still, to account for the clustering of individuals within clusters, coefficients in the regression models at stage three are estimated with cluster-robust standard errors (using the 'vce(cluster)' option in Stata; Froot, 1989). Rather than focusing solely on significance at the 5 per cent level - a practice likely to lead to 'significance fishing' - we report significance at the 1 per cent, 5 per cent and 10 per cent levels, and interpret them accordingly. Significance tests for stages one and two were conducted using Wald tests following descriptive analyses (using the command TEST); results for stage three are presented using average marginal effects, which are less subject to several common misinterpretations (Mood, 2010). 
Table 1 Overlap in food insecurity measures across sample EQLS countries in 2003/2007

\begin{tabular}{lll}
\hline \hline & $\begin{array}{l}\text { Not run out of } \\
\text { money for food (\%) }\end{array}$ & $\begin{array}{l}\text { Run out of money } \\
\text { for food (\%) }\end{array}$ \\
\hline Can afford meat/fish & 78.2 & 6.9 \\
Can't afford meat/fish & 8.7 & 6.3 \\
\hline \hline
\end{tabular}

Notes: Data Source: EQLS 2003-11, $\mathrm{n}=30,507, \mathrm{chi}^{2}$ 7.9e+03, $\mathrm{p}<0.01$.

\section{Results}

Convergent validity of measures of household food insecurity

To test the conceptual validity of our main variable (ability to afford a meal with meat, chicken or fish every other day) we compare it with another indicator of food insecurity in the EQLS (ran out of money to buy food over the past twelve months). Table 1 shows that there is considerable overlap between these variables amongst our sample of countries, suggesting that despite likely cultural relativities in how countries interpret food insecurity, overall our main indicator provides a reasonable proxy for the concept in Europe. Thus it appears to be conceptually valid as a measure of general patterns of food insecurity.

We also check whether in 2003-7, the convergent validity of our two variables is better or worse in specific European countries. This is shown in Table 2 via descriptive statistics and a tetrachoric measure of correlation, which treats variables as binary rather than continuous, to avoid underestimation of the true correlations. This shows strong, statistically significant associations between the two variables in each European country. In certain countries, such as Spain and Italy, correlations are slightly lower $(0.32$ and 0.30 , respectively), perhaps because eating meat/chicken/fish is less central to the definition of a full meal and therefore is less closely associated with running out of money for food. Nonetheless, Table 2 shows that even when we disaggregate by country, our two variables strongly converge with one another.

Finally and most crucially given our concern with trends in food insecurity, we examine the associations between changes in both variables between 2003 and 2007. Figure 1 illustrates how changes within countries map on to each other. In several countries (e.g. Ireland and Finland), the trends in both measures were fairly similar. However, in the case of Portugal and Greece, while there was a decline in both measures, the 'ran out of money for food' decline was much greater. In Estonia, the opposite was the case - the decline was approximately six percentage points greater for the 'meat/chicken/fish' measure. And there were no similarities in the trends in Austria, where there was a 5.5 per cent decrease in those who reported running out of money for food.

We therefore interpret the Austrian, Portuguese, Greek and Estonian trends after 2007 with particular caution. We would also have benefited greatly from the inclusion of the 'ran out of money for food' variable in 2011 and therefore recommend the inclusion of this variable in the 2015 wave of the EQLS to strengthen future research in this field.

In sum, we find substantial convergent validity between our two indicators of food insecurity, although country-level trends for 2003 to 2007 in the meat/chicken/fish 
Table 2 Convergent validity of food insecurity variables across sample countries in $2003 / 2007$

\begin{tabular}{llccll}
\hline \hline & & $\begin{array}{l}\text { Can't afford } \\
\text { meat/fish } \\
(\%)\end{array}$ & $\begin{array}{l}\text { Run out of } \\
\text { money for } \\
\text { food }(\%)\end{array}$ & $\begin{array}{l}\text { Within- } \\
\text { country } \\
\text { correlation }\end{array}$ & Negime \\
\hline Anglo-Saxon & Country & 3.7 & 5.2 & $0.53^{* * *}$ & 2,485 \\
Anglo-Saxon & Ireland & 2.5 & 6.0 & $0.60^{* * *}$ & 1,948 \\
Scandinavian & Sweden & 1.3 & 4.8 & $0.55^{* * *}$ & 2,002 \\
Scandinavian & Denmark & 0.8 & 3.6 & $0.44^{* * *}$ & 1,997 \\
Scandinavian & Finland & 2.0 & 7.0 & $0.58^{* * *}$ & 1,986 \\
Bismarckian & Germany & 4.5 & 15.8 & $0.34^{* * *}$ & 3,036 \\
Bismarckian & Austria & 3.7 & 8.6 & $0.46^{* * *}$ & 2,019 \\
Bismarckian & The Netherlands & 0.7 & 6.2 & $0.46^{* * *}$ & 2,052 \\
Bismarckian & France & 3.1 & 5.3 & $0.58^{* * *}$ & 2,553 \\
Bismarckian & Belgium & 3.4 & 7.7 & $0.53^{* * *}$ & 1,998 \\
Southern & Spain & 2.6 & 4.3 & $0.32^{* * *}$ & 2,008 \\
Southern & Portugal & 8.9 & 8.6 & $0.57^{* * *}$ & 1,968 \\
Southern & Greece & 18.0 & 13.7 & $0.48^{* * *}$ & 1,987 \\
Southern & Italy & 2.4 & 11.1 & $0.30^{* * *}$ & 2,468 \\
Eastern & Czech Rep. & 16.0 & 6.0 & $0.59^{* * *}$ & 2,179 \\
Eastern & Estonia & 15.1 & 13.8 & $0.57^{* * *}$ & 1,593 \\
Eastern & Poland & 15.9 & 17.6 & $0.64^{* * *}$ & 2,440 \\
Eastern & Slovenia & 6.1 & 4.2 & $0.56^{* * *}$ & 1,622 \\
Eastern & Slovakia & 27.2 & 8.5 & $0.59^{* * *}$ & 2,120 \\
Eastern & Hungary & 33.0 & 9.4 & $0.50^{* * *}$ & 1,974 \\
\hline \hline
\end{tabular}

Notes: Data Source: EQLS, 2003-11, all variables independent, ${ }^{* * *} \mathrm{p}<0.01 .{ }^{1}$ 'Correlation' $=$ tetrachoric correlation, suitable for binary variables.

variable are not necessarily mirrored in our other indicator (ran out of money to buy food).

The impact of the crisis on food insecurity in Europe

We turn now to trends over the 2008 crisis in respondents reporting food insecurity, as measured by the meat/chicken/fish variable. First, we investigate variations in trends across European countries in 2003/2007/2011 for our sample as a whole, weighting for population differences across countries (see Table 3). Overall, we observe a significant rise of 2.6 per cent (6.1 to 8.7 per cent) from pre- to post-crisis, yet substantial crosscountry variation is also revealed (a direct test of cross-country differences in trends is highly significant, $\mathrm{p}<0.001)$. In total, eleven of the twenty-one countries had statistically significant changes in food insecurity, although in Denmark and Italy this significance was only at the 10 per cent level. From 2003 to 2011, highly significant rises are shown in the UK (4.2 to 8.8 per cent), the Netherlands (0.3 to 2.0 per cent), France (3.2 to 7.1 per cent), Spain (2.4 to 6.5 per cent), Austria (2.4 to 4.1 per cent), Slovenia (5.6 to 10.1 per cent) and Hungary (34.3 to 41.2 per cent). In Portugal, food insecurity declined from 14.7 to 10.4 per cent between 2003 and 2011, although this was due to a substantial (and significant) decline from 2003 to 2007 (14.7 per cent to 3.3 per cent), followed by 


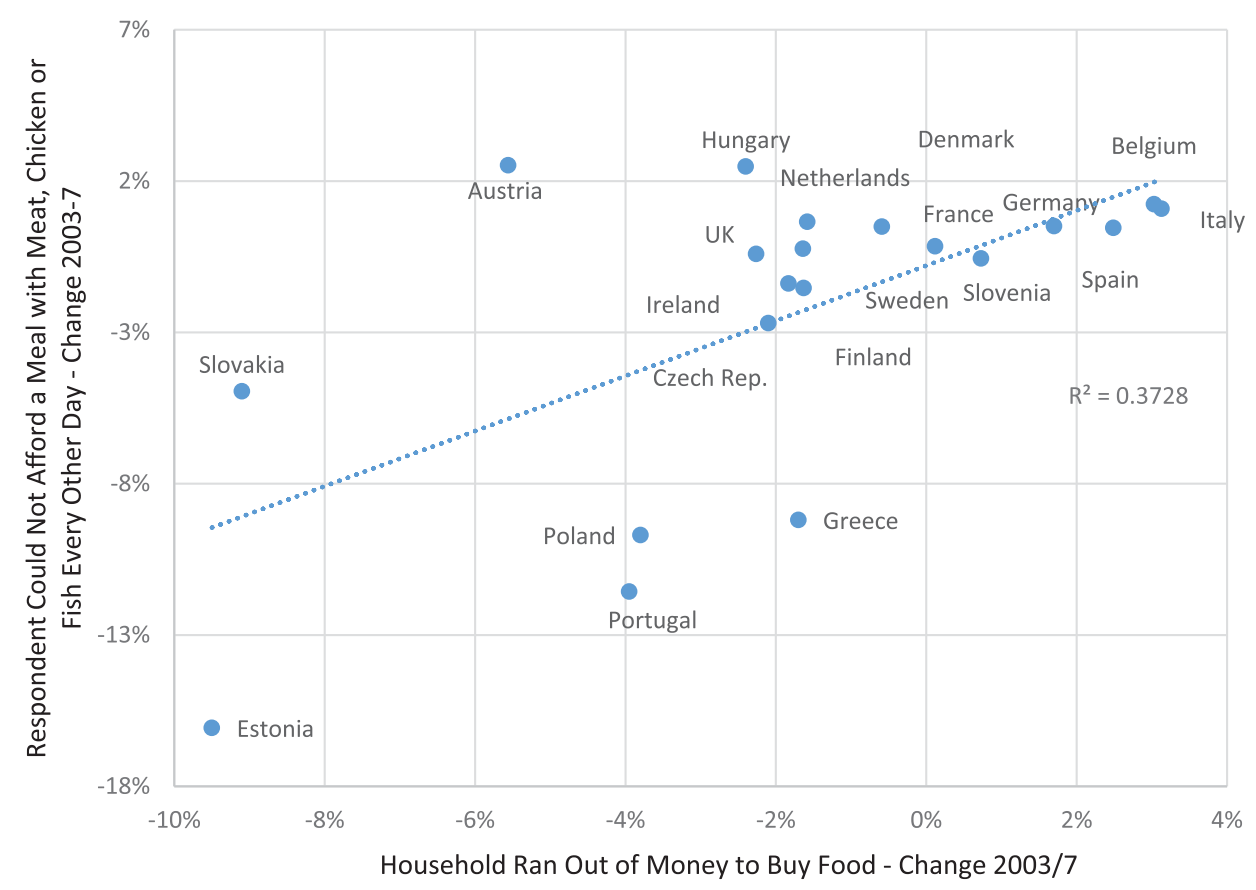

Figure 1. (Colour online) Association of country-level trends 2003-7 in two measures of food insecurity

a rise to from 2007 to 2011 (to 9.0 per cent). Tests also showed that the rises in Portugal, Greece, Estonia and Poland from a combined pre-crisis (2003/7) level to 2011 were highly significant. In Austria, food insecurity rose from 2.4 to 4.9 per cent between 2003 and 2007 and showed no significant change from 2007 and 2011 (as confirmed through further tests). However, below we suggest caution in interpreting this since in Austria there were earlier (2003 to 2007) divergences between the two indicators of food insecurity (see above).

Overall, these results offer strong support for our first hypothesis: there appears to have been a rise in food insecurity since the 2008 crisis which has varied across European countries. This parallels analysis of the EU-SILC by Pfeiffer et al. (2015), in so far as we find a significant rise in the UK and across Europe. However, our analysis contradicts the finding that in Germany food insecurity declined, and the small rise we find in Greece is non-significant. We also find moderate consistency in the reporting of food insecurity with other 'indirect' evidence (Riches, 1996b); in the UK and France, for instance, the large rises are reflected in food bank data from The Trussell Trust and Restos du Coeur. Similarly, the substantial rises in Spain and Portugal (between 2007 and 2011) may be expected given the major increases in unemployment in these countries (Eurostat, 2015).

To investigate variation in trends in food insecurity across welfare regimes, we now cluster countries according to Ferrera's (1996) welfare regime typology with the addition of a group of Eastern countries, as shown in Table 4. The values in the table represent average marginal effects pre-crisis (combining the 2003 and 2007 waves) vs. post-crisis (2011). We show first, in an unadjusted model, that there were highly significant rises 
Table 3 Trends in proportion unable to afford meat/chicken/fish, 2003-11

\begin{tabular}{|c|c|c|c|c|c|c|}
\hline Welfare regime & Country & $\begin{array}{l}\text { Baseline: } \\
2003(\%)\end{array}$ & 2007 (\%) & $\begin{array}{l}\text { Pre-crisis } \\
2003 / 7(\%)\end{array}$ & $\begin{array}{l}\text { Post-crisis } \\
2011 \text { (\%) }\end{array}$ & $N$ \\
\hline Anglo-Saxon & UK & 4.2 & 3.6 & 3.8 & $8.8^{* * *}$ & 4,745 \\
\hline Anglo-Saxon & Ireland & 3.4 & $1.9^{*}$ & 2.6 & 3.5 & 3,024 \\
\hline Scandinavian & Sweden & 1.4 & 1.2 & 1.3 & 2.1 & 3,013 \\
\hline Scandinavian & Denmark & 0.5 & 1.0 & 0.8 & $1.5^{*}$ & 3,023 \\
\hline Scandinavian & Finland & 2.8 & $1.3^{* *}$ & 2.0 & 3.9 & 3,006 \\
\hline Bismarckian & Germany & 4.5 & 4.6 & 4.6 & 5.7 & 6,094 \\
\hline Bismarckian & Austria & 2.4 & $4.9^{* * *}$ & 3.7 & $4.1^{* *}$ & 3,064 \\
\hline Bismarckian & Netherlands & 0.3 & 1.0 & 0.7 & $2.0^{* * *}$ & 3,065 \\
\hline Bismarckian & France & 3.2 & 3.1 & 3.1 & $7.1^{* * *}$ & 4,828 \\
\hline Bismarckian & Belgium & 2.8 & 4.0 & 3.4 & 3.8 & 3,023 \\
\hline Southern & Spain & 2.4 & 2.9 & 2.6 & $6.5^{* * *}$ & 3,523 \\
\hline Southern & Portugal & 14.7 & $3.3^{* * *}$ & 9.0 & $10.4^{* * *}$ & 2,990 \\
\hline Southern & Greece & 22.6 & $13.5^{* * *}$ & 18.0 & 21.2 & 2,990 \\
\hline Southern & Italy & 1.7 & 2.8 & 2.4 & $2.9^{*}$ & 4,738 \\
\hline Eastern & Czech Rep. & 17.9 & 15.3 & 16.5 & 16.7 & 3,205 \\
\hline Eastern & Estonia & 26.2 & $9.3^{* * *}$ & 15.5 & 27.8 & 2,595 \\
\hline Eastern & Poland & 18.2 & $14.6^{* *}$ & 16.0 & 20.4 & 4,684 \\
\hline Eastern & Slovenia & 5.6 & 6.4 & 6.1 & $10.1^{* * *}$ & 2,626 \\
\hline Eastern & Slovakia & 32.7 & $22.9^{* * *}$ & 27.6 & $25.9^{* * *}$ & 3,124 \\
\hline \multirow[t]{2}{*}{ Eastern } & Hungary & 34.3 & 32.0 & 33.1 & $41.2^{* * *}$ & 2,984 \\
\hline & Sample average & 6.5 & $5.6^{* * *}$ & 6.1 & $8.7^{* * *}$ & 70,344 \\
\hline
\end{tabular}

Notes: Data Source: EQLS, 2003-2011. Significance stars refer to change in 2007 and 2011 vs. baseline year of 2003: ${ }^{* * *} p<0.01,{ }^{* *} p<0.05,{ }^{*} p<0.10$.

Table 4 Trends in proportion unable to afford meat/chicken/fish over the crisis across Welfare Regimes

\begin{tabular}{lcccccr}
\hline \hline & $\begin{array}{c}\text { Unadjusted models Average } \\
\text { marginal effects }\end{array}$ & & \multicolumn{2}{c}{$\begin{array}{c}\text { Adjusted models Average } \\
\text { marginal effects }\end{array}$} & \\
\cline { 2 - 3 } Welfare Regime & $\begin{array}{l}\text { Pre-crisis } \\
(\%)\end{array}$ & $\begin{array}{l}\text { Post-crisis } \\
(\%)\end{array}$ & & $\begin{array}{l}\text { Pre-crisis } \\
(\%)\end{array}$ & $\begin{array}{l}\text { Post-crisis } \\
(\%)\end{array}$ & $N$ \\
\hline Anglo-Saxon & 3.7 & $8.4^{* * *}$ & & 3.7 & $8.4^{* * *}$ & 7,812 \\
Scandinavian & 1.3 & $2.4^{* * *}$ & & 1.3 & $2.4^{* * *}$ & 9,070 \\
Bismarckian & 3.6 & $5.7^{* * *}$ & & 3.6 & $5.7^{* * *}$ & 20,134 \\
Southern & 4.3 & $6.4^{* *}$ & & 4.2 & $6.5^{* *}$ & 14,319 \\
Eastern & 19.3 & $23.2^{* * *}$ & & 19.2 & $23.5^{* * *}$ & 19,480 \\
Sample average & 6.1 & $8.7^{* * *}$ & & 6.0 & $8.8^{* * *}$ & 70,344 \\
\hline \hline
\end{tabular}

Notes: Data Source: EQLS, 2003-2011, ${ }^{* * *} p<0.01,{ }^{* *} p<0.05,{ }^{*} p<0.1$. 'Post-crisis' compares the average predicted probability of reporting food insecurity in 2011 against an averaged predicted probability of reporting food insecurity across 2003 and 2007 combined ('Pre-crisis'). The 'Adjusted Model' controls for age, gender, and single parent status. Coefficients for the control variables can be found in the web appendix. 
within each welfare regime, with the steepest rises occurring in the Anglo-Saxon regime where the proportion more than doubled. In terms of overall post-crisis prevalence of food insecurity, the Eastern regime scored worst (23.2 per cent), followed by Anglo-Saxon, Southern, Bismarckian and Scandinavian regimes. As expected, the Eastern countries perform considerably worse than the other regimes overall; however, the post-crisis rise was less substantial in this cluster. Yet individual countries, such as Estonia (albeit statistically insignificant, 15.5 to 27.8 per cent) and Hungary (33.1 to 41.2 per cent) had noticeable rises, perhaps reflecting the fact that while overall the consequences of crisis were bad in this region, specific countries (e.g. Estonia/Hungary) suffered particularly badly (Eurostat, 2015). Alternatively, the findings may suggest that, given the universal welfare state traditions in these countries, social policy plays a role in protecting against the consequences of economic shocks, even where levels of need are high.

Consistent with our original hypothesis, we find that Bismarckian and Scandinavian regimes had the lowest prevalence of food insecurity and small post-crisis rises, yet surprisingly we observe that Anglo-Saxon countries had a sharper post-crisis rise than Southern and Eastern countries, although overall prevalence was high throughout Eastern Europe and in particular Southern countries such as Greece and Portugal. In the AngloSaxon regime - dominated by the UK - food insecurity more than doubled (3.7 to 8.4 per cent), which is surprising as the effects of the crisis were more severe in Southern and Eastern Europe. We offer possible explanations for this in the concluding discussion.

To check that differences between welfare regimes were not due to other factors, we ran an adjusted model which controlled for age, gender and single parent status. The value of including these variables was confirmed as the coefficients (in the web appendix, WA2) showed that women and single parents were significantly more likely to report food insecurity. For age, there was only evidence that younger people (aged eighteen to twentyfour) were less likely to be food insecure than their older counterparts. Table 4 shows that post-crisis changes in food insecurity remained significant net of these factors across each regime and overall post-crisis prevalence followed the same pattern as in the unadjusted analysis - Eastern, Anglo-Saxon, Southern, Bismarckian and Scandinavian.

Overall, our results show that food insecurity has risen across all regimes, yet contrary to expectations, the predicted probability of reporting food insecurity rose most sharply in the Anglo-Saxon rather than Southern and Eastern countries. We also show that the overall prevalence of food insecurity was considerably higher in the Eastern regime throughout 2003-11. Possible explanations for these findings are explored in the concluding discussion.

\section{Sensitivity analysis}

To check the sensitivity of our findings to other methodological decisions, we re-ran the analyses with an alternative weight that counted each country equally within each welfare regime (rather than weighting them by population size). Full results are available in the web appendix (WA3). This produced two notable changes in the results. Prevalence rates in the Anglo-Saxon regime dropped, as the results from Ireland were given greater prominence (see Table 3). We also found that in the Southern regime the post-crisis rise became insignificant, whilst for Anglo-Saxon, Bismarckian, Eastern and Scandinavian regimes it remained highly significant. This may have been because two out of the 
four Southern countries - Italy and Greece - did not show highly significant postcrisis changes. Overall, however, the results when using these alternative weights were similar.

\section{Discussion}

This article has responded to academic and political uncertainty regarding whether food insecurity has risen in Europe within the context of crisis, austerity and rising food bank usage by presenting new evidence on trends in food insecurity 2003-11. It has shown that across many European countries there have been substantial, statistically significant rises in numbers of people reporting an inability to afford a meal with meat, chicken or fish every other day. We have also presented new evidence on rises and overall prevalence of this measure across welfare regimes. We found that the Eastern European countries had the highest overall rates of food insecurity but that the Anglo-Saxon regime had the largest post-crisis rise.

The high reported food insecurity in the Eastern regime may reflect the limitations of the question we use (meat/chicken/fish may not be as highly prioritised in these countries, and a more sensitive measure such as food inadequacy may show a different pattern), but in our view it is more likely to reflect a genuinely lower standard of living in Eastern Europe (Böhnke, 2008). The second key finding, that the rise in food insecurity was sharpest in the Anglo-Saxon regime, is surprising given that the impact of the economic crisis has been less severe in the UK and Ireland than southern Europe. We might attribute this rise in food insecurity to recent policy changes. In particular, our findings could reflect evidence that increased conditionality in the UK benefits system has led to greater food insecurity (Loopstra et al., 2015). It might alternatively represent a greater reliance on familialism in southern Europe during periods of economic strain, where stronger family support networks may provide a buffer against food deprivation (Esping-Andersen, 1999). It could also reflect a greater reliance on short food supply chains in southern Europe (e.g. farmers markets, farm shops etc.).

Our study has several limitations on which it is worth briefly reflecting. First, we were able to investigate trends in only one measure of food insecurity. This is undoubtedly problematic given the multifaceted nature of the concept; for example, countries in southern Europe may have witnessed a lower rise in the deprivation aspect of food insecurity (captured by our meat/chicken/fish variable) than psychological and/or objective aspects. Moreover, because our measure of food insecurity only partially represents the concept, we cannot conclude unequivocally that the rise in food aid reflects rises in all of the dimensions of food insecurity. However, one advantage of the data we use is that we could examine convergent validity between our main measure and an alternative measure which focuses more directly on the sufficiency of food available to an individual rather than the quality of someone's diet (Coates et al., 2006). This showed strong overlaps between the two measures, albeit with the important caveat that country-level trends 2003-7 were not perfectly correlated. We therefore recommend that this further measure of food insecurity is included in the EQLS in future years to enhance the conceptual rigour of empirical work in this field. Since all quantitative measures are only partial representations of the concept (Barrett, 2010), having multiple measures of food insecurity would also enable us to examine how the crisis may have impacted on food insecurity - and 
whether it impacted differently on different aspects of the phenomenon in different countries.

There are several further limitations of our analysis. We cannot discount the possibility that higher demand for food aid will make people more likely to report food insecurity; social desirability bias may make those receiving food aid wish to convince others that they are genuinely food insecure (DeMaio, 1984). Another limitation of this article is that we could only analyse data up to 2011. Since then, there have been further policy changes which might impact on food insecurity (e.g. CPAG, 2013), as well as continuing economic deterioration in parts of Europe (Matsaganis and Leventi, 2014). Finally, comparative survey data suffer from variable non-response biases across countries, and we know, for example, that our sample will have excluded those homeless populations that are disproportionately likely to experience food insecurity.

Despite these issues, to the best of the authors' knowledge, this article is one of only a few articles to provide evidence on differences across countries and welfare regimes in prevalence of food insecurity and trends since the 2008 crisis. It builds on a recent contribution in this journal by Pfeiffer et al. (2015) by comparing a wider range of countries, stratifying by welfare regime and using arguably the best survey for this purpose (EQLS). We hypothesised earlier that trends in food insecurity may differ on the basis of underlying need, in particular in terms of the differential impact of the crisis on poverty, unemployment and underemployment. Our key finding - that food insecurity rose more sharply in Anglo-Saxon than Eastern and Southern countries - does not wholly support this hypothesis. Instead, it suggests that differences in responses to need are important. It implies that variations between welfare regimes in terms of decommodification, stratification and familialism impact on the extent to which they ameliorate the social impacts of crisis (e.g. increased poverty and social inequality) (Esping-Andersen, 1990). These differences may then exert an influence on the food security of citizens, especially during economically tumultuous times.

Although the evidence in this article provides some support for this argument, it could be strengthened by further research with different strengths and weaknesses. Our suggestion that Anglo-Saxon austerity policies may partially account for the rise in food insecurity is supported by Loopstra et al. (2015), but additional research is necessary. Moreover, to improve our understanding of mechanisms linking welfare regimes and food insecurity, research which broadens the scope of our analysis by examining more specifically the areas of the welfare state that matter for food insecurity is highly encouraged. To enable researchers to achieve this, we strongly recommend the inclusion of better measures of multidimensional food insecurity in high-quality datasets such as the EQLS.

\section{Acknowledgements}

Thanks to the data collectors (Intomart GfK, TNS Opinion, Significant GfK) and distributors (UK Data Archive), as well as to Dr Heejung Chung for comments on a draft. The European Quality of Life survey is copyright of the European Foundation for the Improvement of Living and Working Conditions. None of the above is responsible for our interpretation or any errors that remain. 


\section{Note}

1 The 2005 Hartz IV benefit reforms consisted of four laws (Hartz I-IV) implemented between 2003 and 2005. These had a mixture of objectives aimed at renegotiating the relationship between unemployed people and the welfare state (Jacobi and Kluve, 2006: 2). It is argued elsewhere that the Hartz IV law was especially important in changing the institutional structure of German social policy as it integrated unemployment and social assistance, marking a break with the insurance-based traditions of the German welfare state (Fleckenstein, 2008). This affected the long-term unemployed, in particular, who experienced substantial cuts in benefit levels (ibid.: 179).

\section{References}

Avendano, M., Jürges, H. and Mackenbach, J. P. (2009) 'Educational level and changes in health across Europe: longitudinal results from SHARE', Journal of European Social Policy, 19, 4, 301-16.

Barrett, C. (2010) 'Measuring food insecurity', Science, 327, 825-8.

Bhattacharya, J., Currie, J. and Haider, S. (2004) 'Poverty, food insecurity, and nutritional outcomes in children and adults', Journal of Health Economics, 23, 4, 839-62.

Bhattarai, R., Duffy, A. and Raymond, J. (2005) 'Use of food pantries and food stamps in low income households in the United States', Journal of Consumer Affairs, 39, 2, 276-98.

Böhnke, P. (2008) 'Are the poor socially integrated? The link between poverty and social support in different welfare regimes', Journal of European Social Policy, 18, 2, 133-50.

Borjas, G. (2004) 'Food insecurity and public assistance', Journal of Public Economics, 88, 7-8, 1421-43.

Brady, D. (2005) 'The welfare state and relative poverty in rich western democracies, 1967-1997', Social Forces, 83, 4, 1329-64.

Buchanan, R. (2014) 'Almost 50\% of referrals to food banks in the UK are due to "issues with the welfare system"', The Independent, 8 December, http://www.independent.co.uk/news/uk/home-news/ almost-50-of-referrals-to-food banks-in-the-uk-are-due-to-issues-with-the-welfare-system-9910973. html [accessed 26.03.2015].

Butler, P. (2014) 'Need for food banks is caused by welfare cuts, research shows', The Guardian, 8 April, http://www.theguardian.com/society/2014/apr/08/food-bankswelfare-cuts-research [accessed 27.03.2015].

Campbell, C. and Desjardins, E. (1989) 'A model and research approach for studying the management of limited food resources by low income families', Journal of Nutritional Education, 21, 4, 162-71.

Coates, J., Frongillo, A., Rogers, L., Webb, P., Wilde, E. and Houser, R. (2006) 'Commonalities in the experience of household food insecurity across cultures: what are measures missing?', The Journal of Nutrition, 136, 5, 1438S-1448S.

Coleman-Jensen, A., Nord, M., Andrews, M. and Carlson, S. (2013) Household Food Security in the United States in 2012, Washington, DC: USDA, http://www.ers.usda.gov/media/884525/err141.pdf [accessed 12.04.2015].

Cooper, N. and Dumpleton, S. (2013) Walking the Breadline: The Scandal of Food Poverty in 21st Century Britain, Oxford: Oxfam and Church Action on Poverty.

CPAG (2013) Welfare Reform: What it means for Families at Risk of Poverty, London: Child Poverty Action Group.

Daponte, O., Lewis, H., Sanders, S. and Taylor, L. (1998) 'Food pantry use among low income households in Allegheny County, Pennsylvania', Journal of Nutrition Education, 30, 1, 50-7.

Deacon, B. (2000). 'Eastern European welfare states: the impact of the politics of globalization', Journal of European social policy, 10, 2, 146-61.

DeMaio, T. J. (1984) 'Social desirability and survey measurement: a review', in C. F. Turner and E. Martin (eds.), Surveying Subjective Phenomena, 2, 257-82.

Dowler, E. (1998) 'Food poverty and food policy', IDS Bulletin, 29, 1, 58-65. 
Dowler, E. (2002) 'Food and poverty in Britain: rights and responsibilities', Social Policy and Administration, 36, 6: 698-717.

Dowler, E., Kneafsey, M., Lambie, H., Inman, A. and Collier, R. (2011) 'Thinking about "food security": engaging with UK consumers', Critical Public Health, 21, 4, 403-16.

Dowler, E. and Lambie-Mumford, H. (2015) 'How can households eat in austerity? Challenges for social policy in the UK', Social Policy and Society, 14, 3, 417-28.

Eikemo, T. A., Huisman, M., Bambra, C. and Kunst, A. E. (2008) 'Health inequalities according to educational level in different welfare regimes: a comparison of 23 European countries', Sociology of Health and Illness, 30, 4: 565-82.

Esping-Andersen, G. (1990) The Three Worlds of Welfare Capitalism, Cambridge: Polity Press.

Esping-Andersen, G. (1999) Social Foundations of Postindustrial Societies, Oxford: Oxford University Press

European Commission (2012) Main Results of the Distribution Plan in the Last Years, Brussels: EC, http://ec.europa.eu/agriculture/most-deprived-persons/meetings/0507-2012/dgagri1_en.pdf [accessed 05.04.2015].

European Commission (2013) Employment and Social Developments in Europe 2013, Brussels: EC, http://ec.europa.eu/social/main.jsp?catld=738\&langld=en\&publd=7684 [accessed 13.04.2015].

Eurostat (2010) 2010 EU Comparative Final Quality Report, Brussels: EC http://ec.europa.eu/eurostat/ documents/1012329/6064601/2010+EU-FQR.pdf/3ccaea2b-7c1f-4b1c-a8e7-7af1a4284307 [accessed 13.05.2015]

Eurostat (2015) Unemployment Statistics, http://ec.europa.eu/eurostat/statistics-explained/index.php/ Unemployment_statistics [accessed 30.04.2015].

Expactica (2009) 'Crisis sends French new poor flocking to food banks', 27 January, http://www.expatica.com/fr/news/country-news/Crisis-sends-French-new-poorflocking-tofoodbanks_158246.html [accessed 13.04.2015].

Expactica (2013) '121,000 people get help from Food Banks', 18 March, http://www.expatica. com/be/news/country-news/121000-people-get-help-from-FoodBanks_372992.html_ [accessed 13.04.2015].

Fenger, M. (2007) 'Welfare regimes in Central and Eastern Europe: incorporating post-communist countries in a welfare regime typology', Contemporary Issues and Ideas in Social Sciences, 3, 2, 1-30.

Ferrera, M. (1996) 'The "Southern" model of welfare in social Europe', Journal of European Social Policy, $6,1,17-37$.

Fleckenstein, T. (2008). 'Restructuring welfare for the unemployed: the Hartz legislation in Germany', Journal of European Social Policy, 18, 2, 177-88.

Fouarge, D. and Layte, R. (2005) 'Welfare regimes and poverty dynamics: the duration and recurrence of poverty spells in Europe', Journal of Social Policy, 34, 3, 407-26.

Froot, A. (1989) 'Consistent covariance matrix estimation with cross-sectional dependence and heteroskedasticity in financial data', Journal of Financial and Quantitative Analysis, 24, 3, 333-55.

Full Fact (2015) 'More than 1 million people used food banks last year: that's not what the evidence shows', https://fullfact.org/factcheck/economy/food_bank_number-40853 [accessed 13.05.2015]

Hamelin, M., Beaudry, M. and Habicht, P. (2002) 'Characterization of household food insecurity in Quebec: food and feelings', Social Science and Medicine, 54, 1, 119-32.

Hansard Commons (2013) House of Commons c1072, 2 July, http://www.publications.parliament.uk/ pa/ld201314/ldhansrd/text/130702-0001.htm [accessed 13.04.2015].

Hansard Commons (2014) House of Commons c826, 30 April, http://www.publications.parliament.uk/pa/ $\mathrm{cm} 201314 / \mathrm{cmhansrd} / \mathrm{cm} 140430 /$ debtext/404-0001.htm [accessed 13.04.2015].

Jacobi, L. and Kluve, J. (2006) 'Before and after the Hartz reforms: the performance of active labour market policy in Germany', Discussion Paper No. 2100, Institute for the Study of Labor (IZA), Bonn.

Lambie-Mumford, H., Jensen, E., Verbeke, M. and Dowler, E. (2014) Household Food Security in the UK: A Review of Food Aid - Final Report, UK: DEFRA.

Lambie-Mumford, H. and Dowler, E. (2015) 'Hunger, food charity and social policy - challenges faced by the emerging evidence base', Social Policy and Society, 14, 3, 497-506. 
Lansley, S. and Mack, J. (2015) Breadline Britain: The Rise of Mass Poverty, London: One World.

Loopstra, R. and Tarasuk, V. (2012) 'The relationship between food banks and household food insecurity among low-income Toronto families', Canadian Public Policy, 38, 4, 497-514.

Loopstra, R., Reeves, A., Taylor-Robinson, D., Barr, B., McKee, M. and Stuckler, D. (2015) 'Austerity, sanctions, and the rise of food banks in the UK', British Medical Journal, 350, h1775.

Lucas, P., Jessiman, T. and Cameron, A. (2015) 'Healthy start: the use of welfare food vouchers by lowincome parents in England', Social Policy and Society, 14, 3, 457-69.

Matsaganis, M. and Leventi, C. (2014) 'The distributional impact of austerity and the crisis in Southern Europe', South European Society and Politics, 19, 3, 393-412.

Maxwell, G. (1996) 'Measuring food insecurity: the frequency and severity of "coping strategies"', Food Policy, 21, 3, 291-303.

Maxwell, S. and Frankenberger, T. (1992) Household Food Security: Concepts, Indicators, Measurements - A Technical Review, New York and Rome: UNICEF and IFAD.

McKay, S. (2004) 'Poverty or preference: what do "consensual deprivation indicators" really mean?', Fiscal studies, 25, 2, 201-23.

Mood, C. (2010) 'Logistic regression: why we cannot do what we think we can do, and what we can do about it', European Sociological Review, 26, 1, 67-82.

Naska, A., Fouskakis, D., Oikonomou, E., Almeida, V., Berg, A., Gedrich, K. and Trichopoulou, A. (2005) 'Dietary patterns and their socio-demographic determinants in 10 European countries: data from the DAFNE databank', European Journal of Clinical Nutrition, 60, 2, 181-90.

Nielsen, A., Lund, T. and Holm, L. (2015) 'The taste of "the end of the month", and how to avoid it: coping with restrained food budgets in a Scandinavian welfare state context', Social Policy and Society, 14, 3, 429-42.

Nolan, B. and Whelan, C. (2010) 'Using non-monetary deprivation indicators to analyse poverty and social exclusion: lessons from Europe?', Journal of Policy Analysis and Management, 29, 2, 305-25.

Ogg, J. (2005) 'Social exclusion and insecurity among older Europeans: the influence of welfare regimes', Ageing and Society, 25, 1, 69-90.

OECD (2014) Society at a Glance 2014, Paris: OECD, http://www.oecd.org/els/soc/OECD2014SocietyAtAGlance2014.pdf [accessed 13.04.2015].

Pfeiffer, S., Ritter, T. and Oestreicher, E. (2015) 'Food insecurity in German households: qualitative and quantitative data on coping, poverty, consumerism and alimentary participation', Social Policy and Society, 14, 483-95.

Radimer, K. L. (1990) 'Understanding hunger and developing indicators to assess it', Ph.D. dissertation, Cornell University, Ithaca, NY.

Riches, G. (1996a) 'Abandoning the right to food', in G. Riches (ed.), First World hunger: Food Security and Welfare Politics, London: Macmillan Press, pp. 46-78.

Riches, G. (1996b) 'Hunger and the welfare state: comparative perspectives', in G. Riches (ed.), First World Hunger: Food Security and Welfare Politics, London: Macmillan Press, pp. 1-14.

Riches, G. (2002) 'Food banks and food security: welfare reform, human rights and social policy - lessons from Canada?', Social Policy and Administration, 36, 6, 648-63.

Selke, S. (2013) 'The rise of foodbanks in Germany is increasing the commodification of poverty without addressing its structural causes', LSE: EUROPP, http://blogs.Ise.ac.uk/europpblog/ 2013/07/11/germany-foodbanks/ [accessed 08.04.2015].

Sen, A. (1983) Poverty and Famines: An Essay on Entitlement and Deprivation, Oxford: Oxford University Press.

Shipman, T. (2014) 'Food bank charity "is misleading the public": claim that $1 \mathrm{~m}$ need food parcels "just self promotion"', The Daily Mail, 17 April, http://www.dailymail.co.uk/news/article-2606573/ Food-bank-charity-misleadingpublic-Claim-1m-need-food-parcels-just-self-promotion.html [accessed 13.04.2015].

Silvasti, T. (2015) 'Food aid - normalising the abnormal in Finland', Social Policy and Society, 14, 3, $471-82$. 
Sosenko, F., Livingstone, N. and Fitzpatrick, S. (2013) 'Overview of food aid provision in Scotland', Edinburgh: Scottish Government, http://www.scotland.gov.uk/Resource/0044/00440458.pdf [accessed 13.04.2015].

Tarasuk, V. and Maclean, H. (1990) 'The food problems of low-income single mothers: an ethnographic study', Canadian Home Economics Journal, 40, 2, 76-82.

Tarasuk, S. and Beaton, H. (1999) 'Household food insecurity and hunger among families using food banks', Canadian Journal of Public Health, 90, 2, 109-13.

Taylor-Gooby, P. (2012) 'Root and branch restructuring to achieve major cuts: the social policy programme of the 2010 UK Coalition Government', Social Policy and Administration, 46, 1, 61-82.

Trichopoulou, A., Naska, A. and Costacou, T. (2002) 'Disparities in food habits across Europe', Proceedings of the Nutrition Society, 61, 4, 553-8.

Trussell Trust (2014) 'The Trussell Trust's UK Foodbank Network' Salisbury: The Trussell Trust, http://www.trusselltrust.org/resources/documents/Press/TT-FoodbankInformation-Pack-2013-14.pdf [accessed 13.04.2015].

Watts, J. and Bohle, G. (1993) 'Hunger, famine and the space of vulnerability', Geo/ournal, 30, 2, 117-25. 